\title{
Полосчатая железорудная формация Балтийского щита (памяти профессора П.М. Горяинова)
}

\author{
Иванюк Г.Ю. ${ }^{1,2}$, Припачкин П.В. ${ }^{1}$ Базай А.В. ${ }^{1,2}$, Михайлова Ю.А., ${ }^{1,}$, Коноплёва Н.Г. \\ Калашников А.O., \\ ${ }^{1}$ Геологическийинститут КНЦРАН, Anamumbl,ivanyuk@admksc.apatity.ru; paul@geoksc.apatity.ru; \\ ylya_korchak@mail.ru; bazai@geoksc.apatity.ru; kalashnikov@geoksc.apatity.ru \\ ${ }^{2}$ Центр наноматериаловедения КНЦРАН, Anamumbl, konoplyova55@mail.ru
}

Аннотация. Представлена генетическая модель полосчатой железорудной формации, построенная на основании результатов 60-летнего изучения геологии, петрографии и минералогии докембрийских железорудных месторождений Балтийского щита группой профессора П.М. Горяинова (1937-2019).

Ключевые слова: проф. П.М. Горяинов; полосчатая железорудная формация; Балтийский щит; генетическая модель.

\section{Banded Iron-Formation of the Fennoscandian Shield (in memory of professor P.M. Goryainov)}

Ivanyuk G.Yu. ${ }^{1,2}$, Pripachkin P.V. ${ }^{1}$, Bazai A.V. ${ }^{1,2}$, Mikhailova Yu.A. ${ }^{1,2}$, Konoplyova N.G. ${ }^{2}$, Kalashnikov A.O. ${ }^{1,2}$

1 Geological institute KSCRAS, Apatity, ivanyuk@admksc.apatity.ru; paul@geoksc.apatity.ru; ylya_korchak@mail.ru; bazai@geoksc.apatity.ru; kalashnikov@geoksc.apatity.ru

${ }^{2}$ Nanomaterials Research Center KSCRAS, Apatity,konoplyova55@mail.ru

Abstract. The article presents a genetic model of the Banded Iron-Formation based on the results of a 60-year study of the geology, petrography and mineralogy of the Precambrian iron-ore deposits of the Baltic Shield by the scientific group of Professor P.M. Goryainov (1937-2019).

Key words: Prof. P.M. Goryainov; Banded Iron-Formation; Baltic Shield; genetic model.

\section{введение}

Вот уже на протяжении столетия породы полосчатой железорудной формации (ПЖФ) являются объектом пристального внимания исследователей, поскольку они концентрируют в себе основные проблемы докембрийской геологии и являются основным источником железа для мировой промышленности. Особенно активно дискуссия о происхождении ПЖФ велась в 1950-60 годы, что было инициировано, прежде всего, работами Н.М. Страхова и Г. Джеймса об экзогенно-осадочном генезисе кремнисто-железорудных толщ. Альтернативная точка зрения о существенном вкладе подводных фумарольных источников в мобилизацию и накопление железа представлена в работах А. Гудвина, Н.С. Шатского, Р.К. Морриса, М.С. Точилина и других исследователей, включая П.М. Горяинова (1964, 1976, 1988, 1990).

В конце ХХ-столетия геологическое сообщество в большинстве своём признало вулканогенноосадочный генезис пород ПЖФ, примитивность и постоянство их химического и минерального состава, после чего интерес к этим образованиям стал быстро угасать. Дискуссия о происхождении высокометаморфизованных железистых кварцитов Балтийского щита к этому времени также потеряла остроту, поскольку (Горяинов и др., 1990, стр. 150): «... чем большее число подсистем рассматриваемой системы («железорудная формация») попадало в наше поле зрения, тем дальше от согласования представала причинно-генетическая схема. Всё отчётливее вырисовывалась альтернатива: либо пренебречь некоторыми, хотя и согласованными между собой свойствами ради того, чтобы все остальные объединить в рамках общепринятых подходов, либо оставить всё как есть, но отказаться от попыток «втиснуть» их, все самые разнообразные свойства как части сложноорганизованного, упорядоченного сообщества, в детерминистские генетические конструкции (например, метаморфическую осадочно-вулканогенную). То есть отдать предпочтение структурно-организационным аспектам исследования, а не традиционным историческим». 


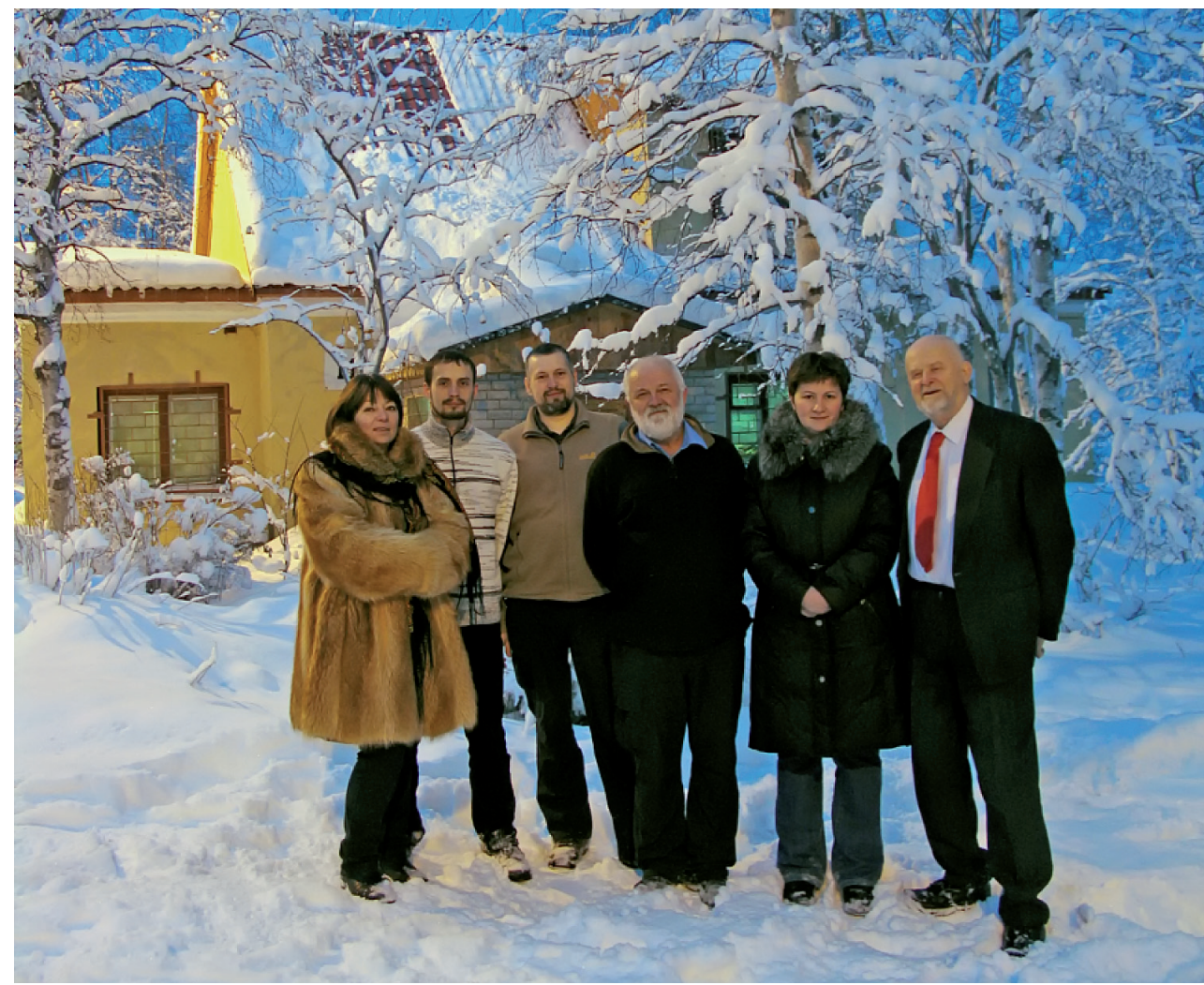

Профессор П.М. Горяинов (крайний справа) со своими учениками.

Professor P.M. Goryainov (right) with his pupils.

В рамках структурно-организационного подхода нами под руководством профессора Горяинова (рисунок) были изучены геологическое строение отдельных месторождений и всего ареала ПЖФ Балтийского щита (Goryainov, 1990; Припачкин, 1994; Goryainov, Ivanyuk, 1998, 2003; Golikov et al., 1999; Горяинов и др., 2001; Ivanyuk, Goryainov, 2008; Bazai et al., 2009), особенности их петрография и минералогии (Балабонин, Иванюк, 1995; Иванюк и др., 1994, 2001, 2005а-в, 2006; Bazai et al., 2009) и сделаны общие выводы об эволюции докембрийских железорудных систем (Горяинов, Иванюк, 2001; Иванюк и др., 1996, 2009; Goryainov et al., 1992, 1997 a, b, 2006). Нам удалось показать, что за кажущейся примитивностью геохимического и минерального спектра железных руд кроется огромная генетическая и технологическая информация, что сделало возможным и актуальным обобщение всех накопленных данных о железных рудах и разработку современной генетической модели ПЖФ в итоговой книге П.М. Горяинова «Полосчатая железорудная формация Балтийского щита». В этой краткой заметке мы как ученики профессора Горяинова (1937-2019) постараемся обрисовать основные положения сформировавшейся под его руководством концепции железного рудообразования в докембрийских вулканогенно-осадочных комплексах.

\section{Геология}

Породы кольской ПЖФ в виде фрактального кластера размерности 2.5-2.7 «цементируют» разномасштабные тоналитовые линзы Кольско-Норвежского мегаблока; крупные тоналитовые овалы в его ЮВ части разделены сравнительно мощными (до 5 км) ветвями этого кластера с крупными месторождениями железистых кварцитов, а мелкие линзы тоналитов в его С3 части рассекаются тонкими (до 500 м) «отростками» с мелкими месторождениями и рудопроявлениями железистых кварцитов. Фрактальная размерность железорудных структур изменяется в пределах 2.2-2.7, в целом соответствуя размерности природных и модельных трещинных/перколяционных кластеров (Goryainov et al., 1997a; Goryainov, Ivanyuk, 1998, 2003; Горяинов, Иванюк, 2001; Ivanyuk, Goryainov, 2008). Возраст тоналитовых гнейсов по данным U-Pb датирования составляет 2.8 млрд. лет, пород ПЖФ - 2.8-1.9 млрд. лет (Иванюк и др., 2009). 
Все месторождения ПЖФ сложены одиночными или объединёнными в достаточно компактные гломеры линзовидными телами железистых кварцитов самого разного размера (мощностью от нескольких десятков сантиметров до 300 м и протяженностью от нескольких метров до 3 км), окруженными зональной гнейсово-амфиболитовой (士 мраморы) толщей пород ПЖФ (Goryainov, 1990; Goryainov, Ivanyuk, 1998, 2003; Goryainov et al., 2006; Иванюк и др., 2009). На слабометаморфизованных месторождениях Сев. Финляндии и Швеции наблюдается постепенный переход от вмещающих апобазальтовых скаполито-тремолито-диопсидовых скарноидов к неяснополосчатым магнетито-серпентиновым рудам, с наименьшим количеством реликтов скарноидов и максимальной концентрацией магнетита в приповерхностных частях рудных тел (Ivanyuk et al., 2017). Рудные тела высоко метаморфизованных железистых кварцитов Мурманской области имеют резкий контакт с вмещающими гнейсами и характерную текстурно-вещественную зональность (от оси к периферии): плойчатые гематито-магнетитовые железистые кварциты с тальком и тремолитом плойчатые магнетитовые железистые кварциты с актинолитом и грюнеритом - прямополосчатые магнетитовые и сульфидно-магнетитовые железистые кварциты с грюне-ритом, геденбергитом и роговой обманкой - различные рудные метасоматиты (магнетито-клинопироксеновые, магнетитокальцито-доломитовые грюнерито-роговообманковые, биотито-альмандино-роговообманковые, эпидото-андрадито-клинопироксеновые, и др.) - двуслюдяные и нодулярные гнейсы с участками силлиманитсодержащих кварцитов и эпидозитов (Golikov et al., 1999; Goryainov, Ivanyuk, 1998, 2003; Горяинов, Иванюк, 2001; Иванюк и др., 2009).

\section{Геохимия}

Аналогично петрографической зональности рудных тел, в слабометаморфизованных комплексах ПЖФ наблюдается постепенное нарастание содержания $\mathrm{Fe}, \mathrm{S}$ и $\mathrm{Cl}$ за счёт $\mathrm{Na}, \mathrm{K}, \mathrm{Ca}$ и $\mathrm{Al}$ при переходе от вмещающих скарноидов к магнетито-серпентиновым рудам, a $\mathrm{Mg}$ и $\mathrm{Si}$ преимущественно концентрируются в промежуточной флогопито-серпентиновой зоне. В высокометаморфизованных комплексах содержание Si тоже незначительно возрастает от осевой зоны рудных тел к контактам с тоналитами, $\mathrm{Fe}$ концентрируется в осевой зоне, $\mathrm{Mg}, \mathrm{Ca}$ и $\mathrm{S}$ - в промежуточных, а $\mathrm{Al}$ и щелочные металлы - в периферийных (Горяинов, 1976; Горяинов, Балабонин, 1988; Иванюк и др., 2009; Ivanyuk et al., 2017). Характер распределения указанных элементов в составе конкретной породы говорит об их вероятном привносе из соседних зон. Содержание подавляющего большинства микропримесей возрастает по степенному закону от осевой зоны к периферийным, и лишь $\mathrm{Cl}$ и $\mathrm{Ge}$ концентрируется в самих железистых кварцитах (Горяинов, Иванюк, 2001; Иванюк и др., 2009).

При компонентном анализе данных о среднем составе пород железорудной формации Балтийского щита всегда выделяется 3 группы элементов, трактуемые как «окисная» $\left(\mathrm{Fe}^{2+}, \mathrm{Fe}^{3+}\right)$, «глинистая» (Al, $\mathrm{Na}, \mathrm{K}, \mathrm{Ti})$ и «карбонатная» $(\mathrm{C}, \mathrm{Ca}, \mathrm{Mg}, \mathrm{Mn})$ составляющие первичных осадков. Важно, что картина качественно совершенно не меняется ни в случае анализа, скажем, данных о составе одних только магнетитовых железистых кварцитов, ни одних только биотитовых гнейсов или магнетито-карбонатных пород. Это означает, что все породы формации являются производными какого-то единого процесса, обусловившего указанную зональность (Иванюк и др., 2009).

\section{Генезис}

По аналогии с современным вулканогенно-осадочным процессом можно предположить, что формирование указанной вещественной зональности рудных тел и всей толщи пород ПЖФ обусловлено воздействием восходящего мантийного флюида, обогащённого хлоридами железа, на океанические базальты. Вследствие выщелачивания сульфидного железа из базальтов формируются близповерхностные магнетито-серпентиновые рудные тела штокверкового типа (Ivanyuk et al., 2017), окружённые «выбеленными» базальтами и переполненные минералами серы (пирротин, пирит, валлериит, халькопирит, барит, ангидрит и др.) и хлора (горяиновит, $\mathrm{Ca}_{2} \mathrm{PO}_{4} \mathrm{Cl}^{1}$, хлорапатит, ма-

\footnotetext{
${ }^{1}$ Открыт в 2017 году на железорудном месторождении Сахаваара в Сев. Швеции и назван в честь П.М. Горяинова за его вклад в изучение геологии и петрологии ПЖФ СВ части Фенноскандинавского щита (Ivanyuk et al., 2017).
} 
риалит и др.), а также существенно гематито-кремнистые осадки, формирующие залежи над магнетитовыми штокверками (Иванюк и др., 2009).

Попадание серпентино-магнетитовых и кварцево-гематитовых руд в восходящий поток восстановленного эндогенного флюида, обогащенного $\mathrm{H}_{2}, \mathrm{H}_{2} \mathrm{~S}, \mathrm{SO}_{2}, \mathrm{CO}$ и $\mathrm{CH}_{4}$, приводит к постепенному разрастанию магнетитовой и (карбонато)-сульфидно-магнетитовой зон посредством реакций:

$$
\begin{aligned}
& 3 \mathrm{Hem}+\mathrm{H}_{2}=2 \mathrm{Mag}+\mathrm{H}_{2} \mathrm{O}, \\
& \mathrm{Mag}+3 \mathrm{CO}_{2}+\mathrm{H}_{2}=3 \mathrm{Sid}+\mathrm{H}_{2} \mathrm{O}, \\
& \mathrm{Mag}+4 \mathrm{H}_{2} \mathrm{~S}=2 \mathrm{Po}+2 \mathrm{Py}+4 \mathrm{H}_{2} \mathrm{O} \text { и т.п., }
\end{aligned}
$$

где Hem - гематит, Mag - магнетит, Ро - пирротин, Ру - пирит, Sid - сидерит (Горяинов, 1976; Иванюк и др., 2009). В результате, формируются зональные рудные тела с гематито-магнетитовыми железистыми кварцитами в апикальной части, сульфидно-магнетитовыми железистыми кварцитами в корневой части и магнетитовыми железистыми кварцитами между ними (Goryainov, Ivanyuk, 1998; Golikov et al., 1999; Горяинов, Иванюк, 2001). Превращение неизменённых краевых базальтов шовной зоны в роговообманковые амфиболиты, а «выбеленных» из-за выноса $\mathrm{Fe}, \mathrm{Na}, \mathrm{K}, \mathrm{Ca}$ и др. элементов базальтов в биотитовые гнейсы завершает формирование зональной толщи пород железорудной формации (Иванюк и др., 1996, 2009).

В ходе дальнейшего метаморфизма происходит смена актинолитсодержащих парагенезисов, характерных для (гематито)-магнетитовых железистых кварцитов, на (альмандин)-грюнеритгеденбергитовые парагенезисы сульфидно-магнетитовых железистых кварцитов (Горяинов, 1976; Иванюк и др., 2005а,б, 2006, 2009):

$$
\begin{aligned}
& 7 \mathrm{Fe}-\mathrm{Act}=14 \mathrm{Hed}+3 \mathrm{Gru}+4 \mathrm{Qz}+4 \mathrm{H}_{2} \mathrm{O}, \\
& (3 \mathrm{Fe}-\mathrm{Act}+2 \mathrm{Tr})+15 \mathrm{Hem}=10 \mathrm{Di}+15 \mathrm{Mag}+20 \mathrm{Qz}+5 \mathrm{H}_{2} \mathrm{O}, \text { и т.п. }
\end{aligned}
$$

где Fe-Act - ферроактинолит, Hed - геденбергит, Gru - грюнерит, Qz - кварц, Tr - тремолит. Вынос кремнезёма в окружающие биотитовые гнейсы приводит к их преобразованию в силлиманитсодержащие гнейсы и околорудные диопсидиты (Горяинов, 1976; Иванюк и др., 2009):

$$
\mathrm{Phl}+3 \mathrm{An}+3 \mathrm{Qz}=\mathrm{Mc}+3 \mathrm{Di}+3 \mathrm{Sill}+\mathrm{H}_{2} \mathrm{O}
$$

где An - анортит, Mc - микроклин, Phl - флогопит, Sill - силлиманит.

Возрастание щёлочности межзерновых растворов на регрессивном этапе метаморфизма, обусловленной буферными свойствами железорудной системы, позволяет им экстрагировать рассеянные элементы из скарноидов с образованием гидроксокомплексов типа $\mathrm{Na}\left[\mathrm{Me}(\mathrm{OH})_{3}\right]$. Попадая в зону сульфидно-магнетитовых железистых кварцитов и, особенно, сульфидсодержащих скарноидов, такие гидроксокомплексы разрушаются в результате кислотного гидролиза с образованием сульфидов $\mathrm{Cu}, \mathrm{Pb}, \mathrm{Zn}$ и еще более щелочного остаточного раствора:

$$
\mathrm{Na}\left[\mathrm{Me}(\mathrm{OH})_{3}\right]+\mathrm{H}_{2} \mathrm{~S} \rightarrow \mathrm{NaOH}+\mathrm{MeS} \downarrow+\mathrm{H}_{2} \mathrm{O} .
$$

Под действием этого раствора первичные железистые силикаты скарноидов и сульфидномагнетитовых железистых кварцитов (ферроактинолит, железистая роговая обманка, грюнерит, геденбергит) замещаются $\mathrm{Ca}-\mathrm{Na}$ амфиболами, эгирином, андрадитом, шамозитом и гриналитом. На начальных этапах Те оказывается рассеянным в составе сульфидов, а при падении щелочности и температуры растворов по мере их просачивания сквозь железистые скарноиды начинают кристаллизоваться теллуриды Au, Ag и Bi (Bazai et al., 2009; Иванюк и др., 2009).

Выделяющаяся в ходе всех вышеприведённых реакций вода приводит к развитию силикатного карста и формированию многочисленных минерализованных пустот, гидротермальных жил и гнёзд с пумпеллиитом-Mg, пренитом, кальциевыми цеолитами, таумаситом, ангидритом и гипсом (Иванюк и др., 2001, 2005в, 2009):

$$
\mathrm{An}+2 \mathrm{Qz}+4 \mathrm{H}_{2} \mathrm{O}=\mathrm{Heu},
$$

где $\mathrm{Heu}$ - гейландит-Са, $\mathrm{CaAl}_{2} \mathrm{Si}_{4} \mathrm{O}_{12} \bullet 4 \mathrm{H}_{2} \mathrm{O}$. С этими образованиями связано высокопробное переотложенное золото, формирующее неправильной формы выделения и хорошо образованные кристаллы до 4 мм в диаметре (Golikov et al., 1999; Bazai et al., 2009). 
Анализ условий образования перечисленных выше минеральных ассоциаций показал, что за первые 100 млн. лет температура процессов минералообразования уменьшилась с $600-700^{\circ} \mathrm{C}$ (по данным оценки $P T$-условий образования железистых кварцитов и околорудных гнейсов посредством программы TWQ) до, по крайней мере, $300^{\circ} \mathrm{C}$ (температура плавления самородного висмута, распространённого в сульфидно-магнетитовых железистых кварцитах и скарноидах). Еще через 100 млн. лет произошло полное завершение процессов гидротермального минералообразования, температура которых на конечных стадиях не превышала $100^{\circ} \mathrm{C}$ (предел устойчивости цеолитов и таумасита), - и железорудная система Кольского полуострова достигла современного состояния. Никаких следов более молодых наложенных процессов нами не зафиксировано (Горяинов, Иванюк, 2001; Иванюк и др., 2009).

Исследования проводились в рамках научной темы ГИ КНЦ РАН 0226-2019-0051.

\section{Литература}

1. Балабонин Н.Л., Иванюк Г.Ю. О природе «голубоватого» магнетита из железистых кварцитов Кольского полуострова // Записки ВМО. 1995. 3. С. 61-77.

2. Горяинов П.М. Геология и генезис железисто-кремнистых формаций Кольского полуострова. Л.: Наука. 1976. $145 \mathrm{c}$.

3. Горяинов П.М., Балабонин Н.Л. Структурно-вещественные парагенезисы железных руд докембрия Кольского полуострова. Л.: Наука. 1988. 144 с.

4. Горяинов П.М., Балабонин Н.Л., Тюремнов В.А. Типы железорудных ансамблей и их геомагнитная систематика. Апатиты: Изд. Кольского НЦ АН СССР. 1990. 170 с.

5. Горяинов П.М., Иванюк Г.Ю. Самоорганизация минеральных систем. М.: ГЕОС. 2001. 312 с.

6. Иванюк Г.Ю., Базай А.В., Пахомовский Я.А., Яковенчук В.Н., Горяинов П.М. Низкотемпературные гидротермальные жилы в породах архейской железорудной формации Кольского полуострова // ЗВМО. 2001. № 3. C. 16-28.

7. Иванюк Г.Ю., Горяинов П. М., Егоров Д. Г. Введение в нелинейную геологию. Апатиты: Изд. КНЦ РАН. 1996. $187 \mathrm{c}$.

8. Иванюк Г.Ю., Горяинов П.М., Пахомовский Я.А., Коноплёва Н.Г., Яковенчук В.Н., Базай А.В., Калашников А.О. Самоорганизация рудных комплексов. Синергетические принципы прогнозирования и поисков месторождений полезных ископаемых. М.: ГЕОКАРТ-ГЕОС. 2009. 392 с.

9. Иванюк Г.Ю., Пахомовский Я.А., Базай А.В., Горяинов П.М., Яковенчук В.Н. Пироксены месторождений полосчатой железорудной формации Кольского полуострова // ЗРМО. 2006. 2. С. 82-92.

10. Иванюк Г.Ю., Пахомовский Я.А., Базай А.В., Яковенчук В.Н., Горяинов П.М. Кальциевые амфиболы из пород полосчатой железорудной формации Кольского полуострова // ЗРМО. 2005 а. 4. С. 56-70.

11. Иванюк Г.Ю., Пахомовский Я.А., Базай А.В., Яковенчук В.Н., Горяинов П.М. Минералы группы гранатов из пород полосчатой железорудной формации Кольского полуострова // ЗРМО. 2005 б. 1. С. 82-90.

12. Иванюк Г.Ю., Пахомовский Я.А., Базай А.В., Яковенчук В.Н., Меньшиков Ю.П., Горяинов П.М. Цеолиты из гидротермальных жил в породах полосчатой железорудной формации Кольского полуострова // ЗРМО. 2005 в. № 2. С. $67-75$.

13. Иванюк Г.Ю., Тюремнов В.А., Балабонин Н.Л. О природе магнитной гетерогенности магнетитов из железистых кварцитов // Физика Земли. 1994. № 3. С. 81-87.

14. Припачкин П.В. Количественная оценка структурно-вещественных особенностей железорудных месторождений Приимандровского района Кольского полуострова // Автореф. канд. диссер. Воронеж. 1994. 16 с.

15. Точилин М.С., Горяинов П.М. Геология и генезис железных руд Приимандровского района Кольского полуострова. М.: Наука. 1964. 102 с.

16. Bazai A.V., Ivanyuk G.Yu., Pakhomovsky Ya.A., Goryainov P.M., Yakovenchuk V.N. Native elements in rocks of the Banded Iron Formation, Kola Peninsula // Geology of Ore Deposits. 2009. V. 51(7). P. 525-536.

17. Golikov N.N., Goryainov P.M., Ivanyuk G.Yu., Pakhomovskii Ya.A., Yakovenchuk V.N. Auriferous iron formations of the Olenegorsk deposit (Kola peninsula. Russia) // Geology of Ore Deposits. 1999. V. 41(2). P. 144-151.

18. Goryainov P.M. Precambrian iron ore formations of the Baltic Shield and their role in structuralsubstantial arrangement of the continental crust / Ancient Banded iron formations (regional presentation). Theophrastus publication. S. A., Athens. 1990. P. 251-279.

19. Goryainov P.M., Ivanyuk G.Yu. On genesis of banded iron-formation of the Kola peninsula. Synergetic aspects / Theophrastus' contributions to advanced studies in geology. Vol. II. Theophrastus Publications A.E., Athens, 1998. P. 249-267. 
20. Goryainov P.M., Ivanyuk G.Yu. Self-organized lithosphere: on the fundamentals of a new geological paradigm // Bulletin de la Classe des Sciences. 2003. XIV(1-6). P. 11-23.

21. Goryainov P.M., Ivanyuk G.Yu., Kalashnikov A.O. Synergetics and (or) plate tectonics // Bulletin de la Classe des Sciences. Acadenie Royale de Belgique. 2006. XVII(7-12). P. 209-253.

22. Goryainov P.M., Ivanyuk G.Yu., Sharov N.V. Fractal analysis of seismic and geological data // Tectonophysics, 1997a. 269. P. 247-257.

23. Goryainov P.M., Yegorov D.G. Ivanyuk G.Y. Derivation of a synergetic model for the Precambrian iron quartzites (on the basis of data on iron ore formations in the Kola peninsula) // Russian Geology and Geophysics. 1997 b. 38(9). P. 1527-1534.

24. Goryainov, P.M. Yegorov, D.G. Ivanyuk, G.Y. Structural and Ore Self-Organization in Archaean Iron Formations of the Kola Peninsula // Transactions Doklady Russian Academy of Sciences. Earth Science Sections. 1992. 323 A(3). P. 99-101.

25. Ivanyuk G.Yu., Goryainov P.M. Structural and compositional zoning and formation conditions of the Greater Eastern Litsa BIF occurrence, Kola Peninsula // Geology of Ore Deposits. 2008. 50. P. 670-680.

26. Ivanyuk G.Yu., Yakovenchuk V.N., Pakhomovsky Ya.A., Panikorovskii T.L., Konoplyova N.G., Bazai A.V., Bocharov V.N., Antonov A.A., Selivanova E.A. Goryainovite, $\mathrm{Ca}_{2} \mathrm{PO}_{4} \mathrm{Cl}$, a new mineral from the Stora Sahavaara iron ore deposit (Norrbotten, Sweden) // GFF. 2017. 139. P. 75-82. 